\title{
A simple hydrazine based molecule for selective detection of Fluoride ion in DMSO
}

\author{
ADDITI ROY CHOWDHURY ${ }^{\mathrm{a}, \mathrm{b}}$ and PRIYABRATA BANERJEE ${ }^{\mathrm{a}, \mathrm{b}, *}$ \\ a Surface Engineering \& Tribology Group, CSIR-Central Mechanical Engineering Research Institute, \\ Mahatma Gandhi Avenue, Durgapur 713 209, India \\ ${ }^{\mathrm{b}}$ Academy of Scientific and Innovative Research(AcSIR), CSIR-Central Mechanical Engineering Research \\ Institute (CMERI) campus, Mahatma Gandhi Avenue, Durgapur 713 209, West Bengal, India \\ Email:pr_banerjee@cmeri.res.in; priyabrata_banerjee@yahoo.co.in
}

MS received 10 August 2016; revised 26 December 2016; accepted 27 January 2017

\begin{abstract}
A newly synthesized hydrazine-functionalized Schiff base chemoreceptor $\left[N^{1} N^{3}-\right.$ bis $(4-$ cyanobenzylidene)isophthalahydrazide], NBCBIH has been prepared and successfully utilized for selective detection of Fluoride ion. Herein, $\mathrm{NH}$ and $\mathrm{C}=\mathrm{N}$-like functional units have been incorporated which provide better colorimetric response compared to systems where such kind of units are absent. On exposure to $\mathrm{F}^{-}$, NBCBIH turns from almost colorless to yellow. The recognition is well-supported by UV-Vis, fluorescence and ${ }^{1} \mathrm{H}-\mathrm{NMR}$ in DMSO. The fluorescence quenching is well-explained by photoinduced electron transfer mechanism (PET). The limit of detection of $\mathrm{F}^{-}$with NBCBIH is $0.7 \times 10^{-4} \mathrm{M}$.
\end{abstract}

Keywords. Chemoreceptor; fluoride; colorimetric detection; PET; DFT-D3.

\section{Introduction}

Designed synthesis of artificial organo chemoreceptors for $\mathrm{F}^{-}$(fluoride) ion is an advancing and challenging area of interest. This is because of the huge importance of the bio-benign anion $\mathrm{F}^{-}$. ${ }^{1}$ The level of $\mathrm{F}^{-}$which is necessary in the environment as well as in the human body is about $0.8-1.3 \mathrm{mg} / \mathrm{L}$. This is needed for providing strength to human bones and teeth. However, accumulation of $\mathrm{F}^{-}$in the human body (as fluorapatite) in excess of required amount ${ }^{1-3}$ is a poison and leads to certain diseases like osteoporosis, osteosclerosis, dental fluorosis and skeletal fluorosis. In recent times, the scientific community is looking for chemoreceptors which can detect $\mathrm{F}^{-}$in both chromogenic and photoluminescent way, which is less expensive than the existing physical methods for detection of fluoride and separation. These methods include ion chromatography, ion selective electrodes, and Willard and winter methods, etc., which are in general use for quantitative detection and estimation of $\mathrm{F}^{-}$.

Now, NBCBIH $\left[N^{1} N^{3}\right.$-bis(4-cyanobenzylidene) isophthalahydrazide] based chemoreceptor as a promising contender has been designed and accordingly synthesized considering a few reasons; such as, the $-\mathrm{NH}$ units which are excellent $\mathrm{H}$-bond donors and the $-\mathrm{C}=\mathrm{N}$ linkage whose presence is the driving force for

*For correspondence chromogenic response in the visual range. An additional advantage of this molecule is the presence of $-\mathrm{CN}^{-}$ group at the two para positions of the phenyl ring in the two arms. As it has always been the priority of researchers to synthesize low cost and easy to make organic chemoreceptor for detection of $\mathrm{F}^{-}$selectively, ${ }^{4,5}$ so in this regard our chosen molecule has been quite successful as selective and efficient chemosensor for $\mathrm{F}^{-}$.

Thus, a chemosensor is generated with more than one $-\mathrm{C}=\mathrm{N}$ linkage and more number of dissociable $\mathrm{NH}$ protons in the organic scaffold. The central phenyl ring along with two $-\mathrm{C}=\mathrm{N}$ centers can be treated as the fluorogenic centre and the two NH centers as probable binding units. It is interesting to note that, presence of $-\mathrm{NH}$ sites generate stronger recognition of incoming $\mathrm{F}^{-}$ion where incidental existence of two chromogenic $-\mathrm{C}=\mathrm{N}$ centers provide enhanced colorimetric change with $\mathrm{F}^{-}{ }^{6}$ The nearly flat chemosensor with its two $-\mathrm{NH}$ sites can sense $\mathrm{F}^{-}$in both ways, depending on the number of equivalents of $\mathrm{F}^{-}$added i.e. one equivalent or two equivalents. Cyano substitution easily excludes any sort of electrostatic attraction or repulsion between aromatic unit and $\mathrm{F}^{-}$. The selectivity of NBCBIH towards $\mathrm{F}^{-}$has been fully supported by UV-Vis, fluorescence, IR and ${ }^{1} \mathrm{H}-\mathrm{NMR}$ etc. Notably, other anions like $\mathrm{Cl}^{-}, \mathrm{Br}^{-}, \mathrm{I}^{-}, \mathrm{NO}_{3}^{-}, \mathrm{HSO}_{4}^{-}, \mathrm{CN}^{-}$, etc., are unresponsive. Photoinduced electron transfer (PET) leads to a decrease in fluorescence response as 
a consequence of $\mathrm{F}^{-}$recognition. ${ }^{1} \mathrm{H}-\mathrm{NMR}$ study provides a satisfactory evidence concerning recognition of $\mathrm{F}^{-}$ion where the outward facing NH sites of NBCBIH are hydrogen bonded with $\mathrm{F}^{-}$. Moreover, cyclic voltammetry and IR studies provide supportive evidences for the interaction of NBCBIH with F. The DFT (DFT-D3) study nicely supports the experimental results.

\section{Experimental}

\subsection{Materials and Methods}

All starting materials (chemical reagents, solvents) were purchased and were of analytical grade. Solvents like methanol, acetonitrile were distilled and dried before use. Tetrabutyl ammonium salts fluoride (hydrate), chloride, nitrate, bromide, hydrogen sulfate acetate and phosphate were purchased from Sigma Aldrich and used as received. DMSO was of spectroscopic grade and purchased from Merck India Pvt. Ltd. and used without further purification.

Perkin Elmer FT-IR Spectrum 100 spectrophotometer was used for recording infrared spectra. The mass spectra were taken using Advion's CMS Expression compact mass spectrometer. ${ }^{1} \mathrm{H}$ NMR spectra were recorded in a Bruker AV-400 spectrometer. UV-Vis spectra were recorded in SEC2000, ALS spectrophotometer and Agilent make Cary 60. Fluorescence experiments were performed in Perkin Elmer LS-45 spectrometer. Cyclic voltammetric experiments were carried out in Biologic's SP-150 series instrument.

\subsection{Synthesis of NBCBIH (Scheme 1)}

4-Cyanophenyl hydrazine $(1 \mathrm{mmol})$ was dissolved in methanol $(\sim 20 \mathrm{~mL})$ and stirred for $10 \mathrm{~min} .1,3$ Dialdehyde $(0.5 \mathrm{mmol})$ was dissolved in another solution of methanol $(15 \mathrm{~mL})$ and added slowly to the stirring solution of 4Cyanophenyl hydrazine. The solution was allowed to reflux for next $6 \mathrm{~h}$ (Scheme S1). After completion of the reaction, slow evaporation of the solution gave a very light yellowish product. Slow evaporation of methanol solution of pure NBCBIH produced dark yellow colored crystals after one week. The compound was characterized by elemental analysis, IR, ESI mass, ${ }^{1} \mathrm{H}-\mathrm{NMR}$ and single crystal X-ray analysis (Figures S1-S3 and Tables S1-S4 in Supplementary Information). (Yield: $0.15 \mathrm{~g}, 82 \%$ ): Anal. Calcd. for $\mathrm{C}_{22} \mathrm{H}_{16} \mathrm{~N}_{6}$ : $\mathrm{C}$, $68.2 ; \mathrm{H}, 4.1 ; \mathrm{N}, 21.7 \%$. Found: C, 68.1; H, 3.9, N, 21.59\%. IR $v / \mathrm{cm}^{-1}: 3263 \mathrm{~m}(\mathrm{~N}-\mathrm{H}), 2210 \mathrm{~s}(-\mathrm{C} \equiv \mathrm{N}), 1605 \mathrm{~s}(-\mathrm{C}=\mathrm{N}),(\mathrm{s}$, strong; m, medium). ${ }^{1} \mathrm{H}-\mathrm{NMR}\left(300 \mathrm{MHz}, \mathrm{DMSO}-d_{6}, \mathrm{Me}_{4} \mathrm{Si}\right.$ )
$11.052(\mathrm{~s},-\mathrm{N} H), 8.020(\mathrm{~s}, 2 H), 7.959(\mathrm{~s}, 1 H), 7.71(\mathrm{~d}, 4 H)$, $7.671(\mathrm{~d}, 4 H), 7.181(\mathrm{~d}, 4 H), 7.461(\mathrm{t}, 1 H) .387\left[\mathrm{M}+\mathrm{Na}^{+}\right]$. M.p.: $240^{\circ} \mathrm{C}$.

\section{$2.3 X$-ray crystallography}

The X-ray crystal data were collected in Bruker-AXS SMART APEX II diffractometer at $100 \mathrm{~K}$ equipped with a CCD detector using graphite-monochromated Mo-K $\alpha$ radiation $(\lambda=0.71073 \AA)$. The data were processed with SAINT ${ }^{7}$ and absorption corrections were made with SADABS. ${ }^{7}$ The structure was solved by direct and Fourier methods and refined by full-matrix least-squares based on $F 2$ using the WINGX software which utilizes SHELX-97. ${ }^{8 \mathrm{a}}$ For structure solution and refinement, the SHELXTL software package ${ }^{8 b}$ was used. The nonhydrogen atoms were refined anisotropically, while the hydrogen atoms were placed with fixed thermal parameters at idealized positions.

\subsection{Computational details}

All density functional theory (DFT) calculations were performed with the Turbomole V7. $.0^{9}$ package. In the ground state the geometry was optimized with BP86 function and def-SV(P) basis set. Exchange correlation function LDA + Becke was utilized. Spherical grid size was set to 5 being the most dense. Vibrational frequencies also enable calculation of the molecular partition function and thus prediction of thermodynamic functions at temperatures other than $0 \mathrm{~K}$ and finite pressure (within the assumption of an ideal gas and no coupling between degrees of freedom). Diagonalization of Fock matrix in last SCF iteration was activated. Specification of the sharpness of the partition functions as proposed by Becke with a default nkk-3. The usage of nkk is acceptable within the range of $1 \leq \mathrm{nkk} \leq 6$. The DIIS (DIIS Convergence Acceleration) procedure was implemented to accelerate the optimization. HOMO-LUMO energy gap was calculated. Automatic virtual orbital shift was switched on for $\mathrm{E}(\mathrm{LUMO})-\mathrm{E}(\mathrm{HOMO})<0.10000000$. All the single point energy calculations were carried out at BP86(D3BJ) function/def2-SVP basis set for all the geometries.

\subsection{Calculation of Detection limit}

The limit of detection (LOD) of $\mathrm{F}^{-}$by NBCBIH was calculated based on fluorescence titration experimentation. ${ }^{10}$ The fluorescence emission spectrum of NBCBIH was repeated 10 times and then standard deviation is calculated. The limit

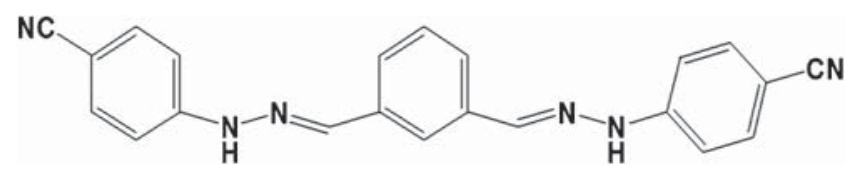

Scheme 1. Structure of $\left[N^{1} N^{3}\right.$ bis(4-cyanobenzylidene)isophthalahydrazide], NBCBIH. 
of detection (LOD) was calculated by using the following formula:

$$
\mathrm{DL}=3 \sigma / \mathrm{k}
$$

where $\sigma$ is the standard deviation of the blank NBCBIH chemosensor. $\mathrm{k}$ is the slope of the plot (Figure S7 in SI) of emission intensity of NBCBIH at $460 \mathrm{~nm} v s$ [TBAF].

\section{Results and Discussion}

The yellow colored crystal of NBCBIH was characterized in solution state by UV-Vis, ${ }^{1} \mathrm{H}$ NMR and ESIMS studies and in solid state by elemental $(\mathrm{C}, \mathrm{H}, \mathrm{N})$ analysis, FT-IR and single crystal X-ray. The crystal structure of NBCBIH is shown in Figure 1. Single crystals of X-ray quality are produced as mentioned in the experimental section. NBCBIH co-crystallized with two water molecules in the triclinic space group P-1 (No.2). NBCBIH is a highly symmetric molecule and the two arms are symmetrically related to carbon atom $\mathrm{C} 10$ of the central phenyl ring which actually resides on the two-fold axis, producing a gliding shape for the chemosensor. In the unit cell, two NBCBIH molecules form a closely packed structure along the crystallographic $c$ axis. Here, the $\mathrm{N}-\mathrm{N}$ distances are $1.364 \AA$ and $1.363 \AA$ whereas $\mathrm{N}-\mathrm{N}$ distance in hydrazine is $1.45 \AA$. The $\mathrm{C}-\mathrm{N}$ bond distances are $1.380 \AA$ and $1.375 \AA$ whereas, in general, the single $\mathrm{C}-\mathrm{N}$ distances are in the range of $1.47 \AA .{ }^{11-13}$ The $\mathrm{C}=\mathrm{N}$ distances are observed to be $1.280 \AA$ and $1.282 \AA$ which is slightly higher than ideal $\mathrm{C}=\mathrm{N}$ distance (i.e., 1.27 $\AA$ ). All these data helped us to conclude that there is sufficient delocalization in the system. The different dihedral angles of the molecule are as follows: $29.73^{\circ}, 159.63^{\circ}, 71.72^{\circ}$, $81.64^{\circ}$ and $27.83^{\circ}$.

The NBCBIH is almost planar. The N5-N4-C15 bond angle is $\sim 117.07^{\circ}$ and $\mathrm{C} 8-\mathrm{N} 3-\mathrm{N} 2$ bond angle is $\sim 117.18^{\circ}$. The $\mathrm{sp}^{2}$ mode of $\mathrm{N} 6$ atom is responsible for strengthening the electron delocalization in the system.

\subsection{UV-Vis spectroscopic analysis}

The spectrum (before addition of $\mathrm{F}^{-}$) for $\mathbf{N B C B I H}$ in DMSO shows peak at $370 \mathrm{~nm}$ (Figure 2) with molar extinction coefficient $\left(\varepsilon_{370} 85000 \mathrm{M}^{-1} \mathrm{~cm}^{-1}\right)$ which may be attributed to $n-\pi *$ transition of the electron localized on azomethine group. ${ }^{14-16}$ This peak intensity diminishes and a new peak at $500 \mathrm{~nm}\left(\varepsilon_{500} 46000 \mathrm{M}^{-1} \mathrm{~cm}^{-1}\right)$ gradually emerges with addition upto $0.1 \mathrm{~mL}$ of $2 \times$ $10^{-4} \mathrm{M}$ of $\mathrm{F}^{-}$ion (Figure 2). The colour turns from almost colorless to yellow (Figure S4 in SI). This is a strong indication regarding the presence of strong hydrogen bonding interaction between $\mathrm{F}^{-}$and NBCBIH and occurrence of charge transfer (CT) transition in the NBCBIH system. A distinct isosbestic point is seen at $\sim 395 \mathrm{~nm}\left(\varepsilon_{395 \mathrm{~nm}} 27000 \mathrm{M}^{-1} \mathrm{~cm}^{-1}\right)$ which indicates the generation of a new species and simultaneous presence of two species in equilibrium. Addition of several other anions, even in excess, (e.g., $\mathrm{Cl}^{-}, \mathrm{Br}^{-}, \mathrm{I}^{-}, \mathrm{HSO}_{4}^{-}, \mathrm{SH}^{-}$, $\mathrm{N}_{3}^{-}$and $\mathrm{NO}_{3}^{-}$) no subtle change in color was observed

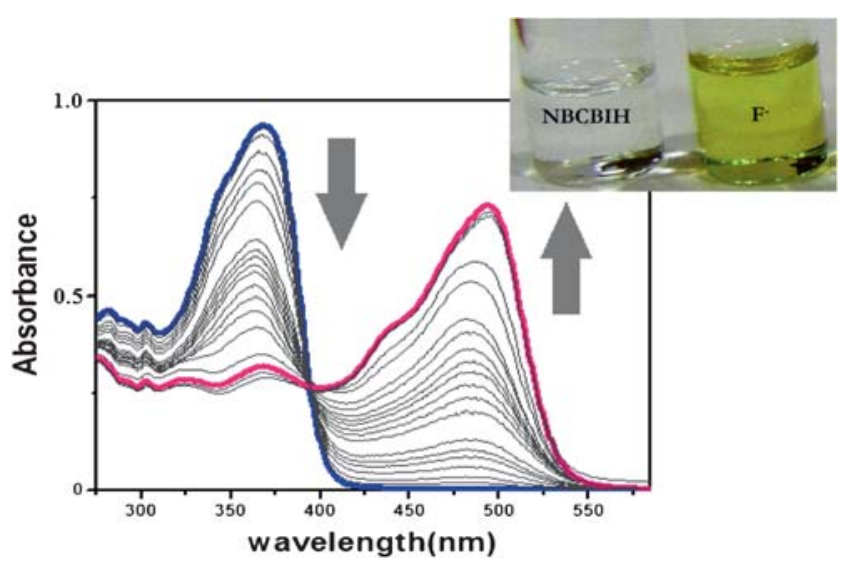

Figure 2. UV-Vis spectral response of NBCBIH $(1 \times$ $\left.10^{-5} \mathrm{M}\right)$ with TBAF in DMSO $\left(2 \times 10^{-4} \mathrm{M}\right)$ upto a total of 100 microlitre addition of the salt. Inset: Color change of NBCBIH in presence and absence of $\mathrm{F}^{-}$.

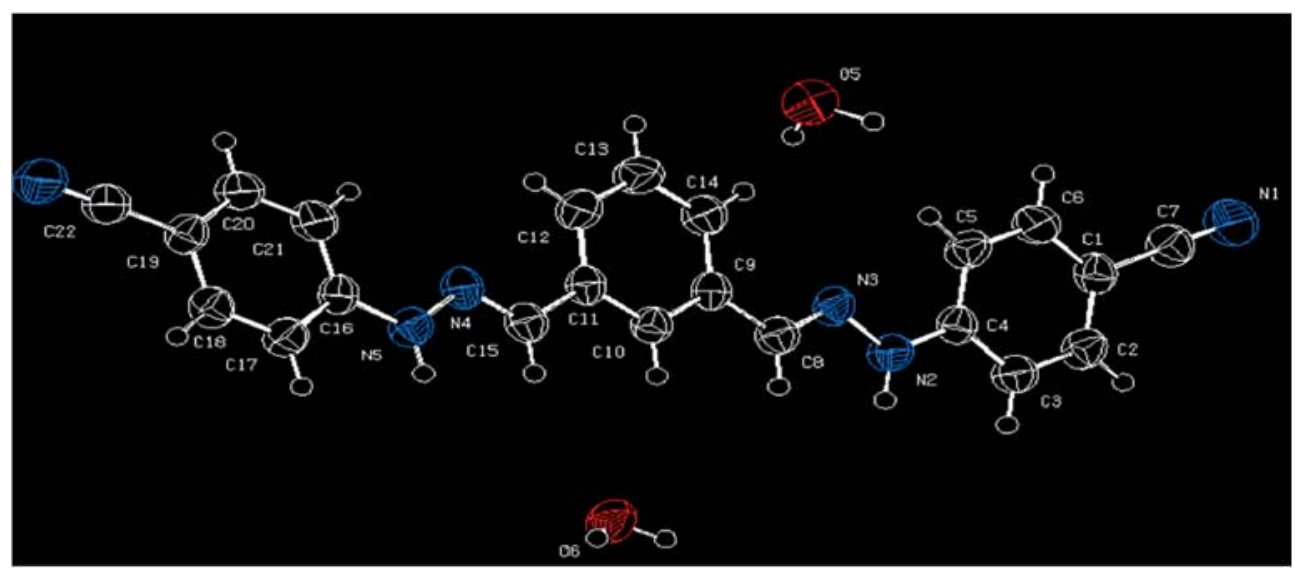

Figure 1. ORTEP diagram with atom numbering of NBCBIH. 
(Figure 3). A very feeble response was observed in case of $\mathrm{AcO}^{-}$. To establish NBCBIH as a fluoride receptor, interference study was carried out for $\mathrm{F}^{-}$with other anions (Figure 3). As an additional study, ESI-MS spectrum of NBCBIH with TBAF is shown in Figure S5 in SI. This adduct may be a combination of (NBCBIH $\left.+\mathrm{Na}^{+}+2 \mathrm{~F}^{-}+2 \mathrm{H}_{2} \mathrm{O}+\mathrm{CH}_{3} \mathrm{CN}\right)$. The binding constant value of NBCBIH with $\mathrm{F}^{-}$is found to be $0.0115 \times 10^{4}$ $\mathrm{M}^{-1}$ from B-H plot $^{17}$ as shown in Figure S8 for 1:1 complex indicated in Job's plot in Figure S9 (in SI). The reversibility of the sensing is shown in the Figure S6 (in SI), which shows that the yellow color of NBCBIH... $\mathrm{F}^{-}$adduct disappears with the addition of $\mathrm{H}^{+}$ions and the color regenerates with addition of $\mathrm{F}^{-}$.

\subsection{Fluorescence analysis}

Like the UV-Vis experiments, the fluorescence titration experimentats were performed in DMSO. NBCBIH shows blue emission at $460 \mathrm{~nm}$ upon excitation at $400 \mathrm{~nm}$. Interestingly, the peak at $460 \mathrm{~nm}\left(\lambda_{\max }\right)$ is enormously red shifted to $550 \mathrm{~nm}$ with gradual addition of TBAF and simultaneously quenched. NBCBIH is a luminescent PET (Photoinduced electron-transfer) based chemosensor with two binding sites having $\mathrm{NH}$ groups along with substituted benzene unit (acceptor) as the fluorophore part. Here, the quenching of NBCBIH can be explained in the light of PET from the electron rich $\mathrm{NH}$ unit to the phenyl ring unit. In general, PET happens between groups where oxidation potential of the incoming guest is lower than that of the fluorophore. ${ }^{18}$ As there is a hydrogen bonding network in between $\mathrm{F}^{-}$and $-\mathrm{NH}$ units, hence it may be responsible for reduction in oxidation potential of the hydrazine linker which in turn triggers PET from hydrazine linkage to the phenyl subunit. Electron transfer between the donor and acceptor is faster because of $\mathrm{H}$-bonding interaction, which in turn increases the electron density in
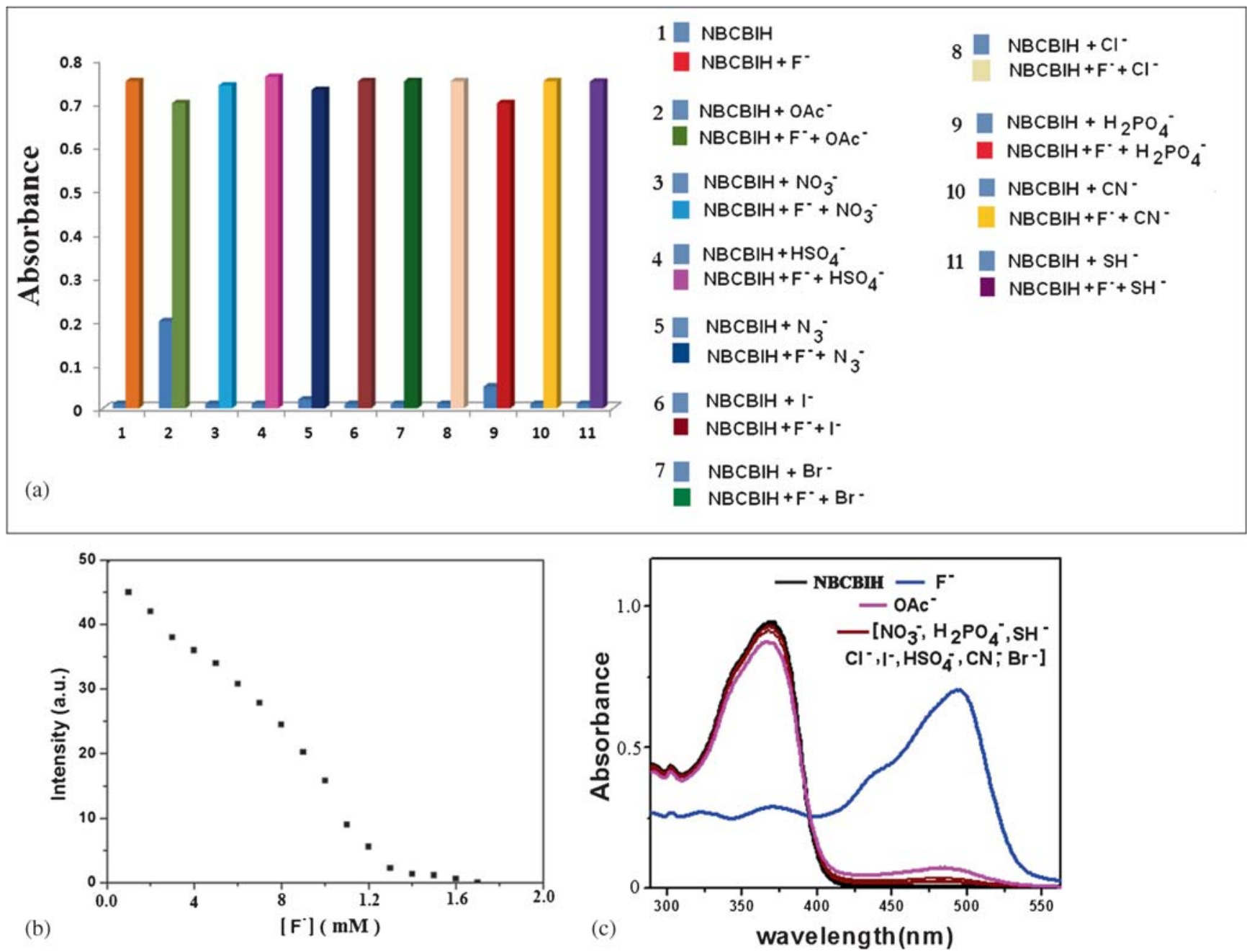

Figure 3. (a) Interference study in detection of $\mathrm{F}^{-}$with NBCBIH in the presence of other anions. (b) Decrease of emission intensity of NBCBIH with increase in $\mathrm{F}^{-}$concentration. (c) Selective detection of $\mathrm{F}^{-}$with $\mathbf{~ N B C B I H}$ in presence of other competitive anions. 
the whole scaffold. With increasing amount of added $\mathrm{F}^{-}$, a red shift is observed. It is a clear indication of simultaneous occurrence of PET and ICT in the system. The feasibility of the PET reaction is further supported by the well-known Rehm-Weller equation $\left(\Delta \mathrm{G}_{\mathrm{PET}}=\right.$ $\left.E_{\text {ox }}(D)-E_{\text {red }}(A)-E_{00}+C\right)^{19}$ where $E_{o x}$ is oxidation potential of the donor (D), $E_{\text {red }}$ is oxidation potential of the acceptor(A), $\mathrm{E}_{00}$ is excited state energy. In this case, $\Delta \mathrm{G}_{\mathrm{PET}}=-1.2 \mathrm{eV}$, with $\mathrm{E}_{\mathrm{ox}}(\mathrm{D})=1.26 \mathrm{~V}, \mathrm{E}_{\mathrm{red}}(\mathrm{A})=$ $-0.566 \mathrm{~V}$ and $\left.\mathrm{E}_{00}=3.02 \mathrm{eV}\right)$. LOD value has been calculated to be $1.8 \times 10^{-6} \mathrm{M}$ via colorimetric (Figure S7 in SI) and $0.7 \times 10^{-4} \mathrm{M}$ via fluorescence (Figure S8), which is in line with reported materials (Figure 4). ${ }^{4 \mathrm{~h}, 20}$

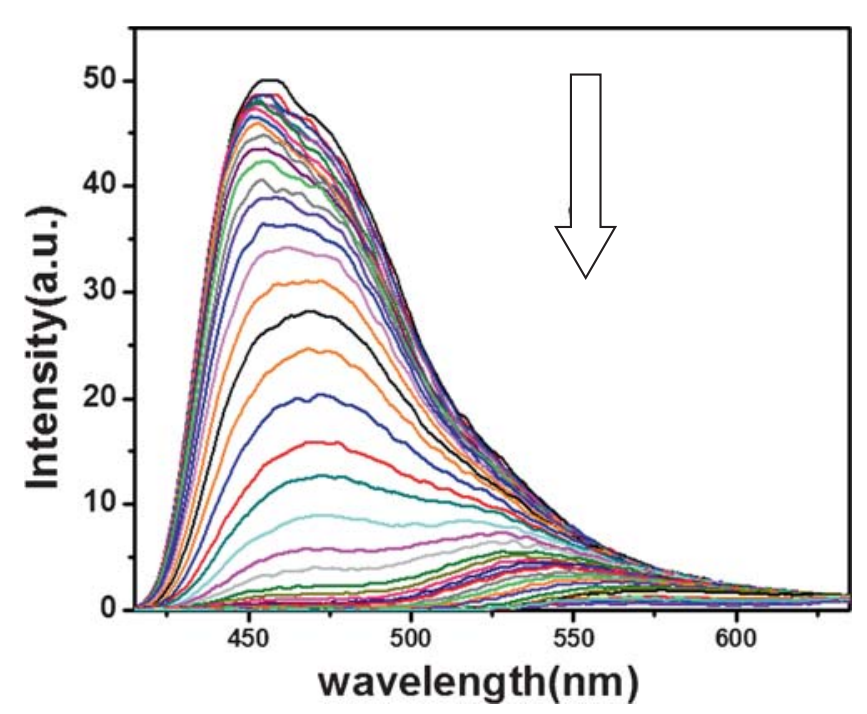

Figure 4. Fluorescence quenching of emission intensity of NBCBIH $\left(1 \times 10^{-5} \mathrm{M}\right)$ and red shift $\left(\lambda_{\mathrm{ex}}\right.$ at $\left.400 \mathrm{~nm}\right)$ with the addition of TBAF $\left(2 \times 10^{-4} \mathrm{M}\right)$.

\section{$3.3{ }^{1} H$-NMR spectroscopic analysis}

To get further insight into the mode of interaction between NBCBIH and $\mathrm{F}^{-}$, the ${ }^{1} \mathrm{H}-\mathrm{NMR}$ spectral changes of NBCBIH with $\mathrm{F}^{-}$were carefully scrutinized (Figure 5). The results obtained from ${ }^{1} \mathrm{H}-\mathrm{NMR}$, finely corroborate with the absorbance and fluorescence findings; i.e., formation of $\mathrm{H}$-bonding interaction between NBCBIH and $\mathrm{F}^{-}$. The $\mathrm{H}$-bonding interaction of NBCBIH polarizes the $\mathrm{N}-\mathrm{H}$ protons with a throughspace effect. ${ }^{21}$ As an artifact, the sharp response at $11.1 \mathrm{ppm}$ undergoes significant reduction in intensity. At 0.1 equivalent of fluoride addition, the $\mathrm{NH}$ proton signal diminishes and disappears completely. $\mathrm{CH}$

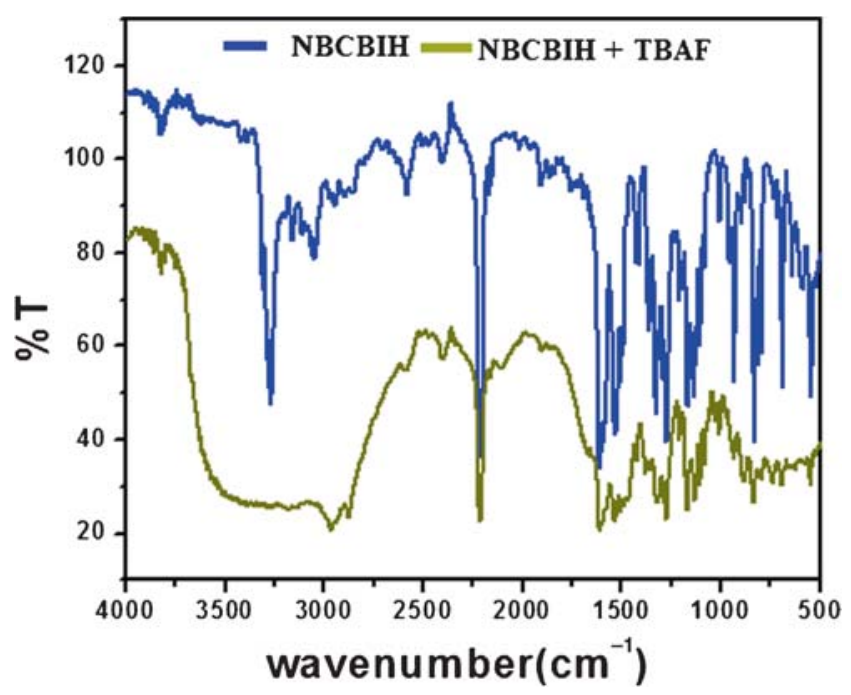

Figure 6. Infrared Spectrum (in $\mathrm{KBr}$ pellet) of NBCBIH $(\sim 5 \mathrm{mg})$ with TBAF $(\sim 2.5 \mathrm{mg})$.

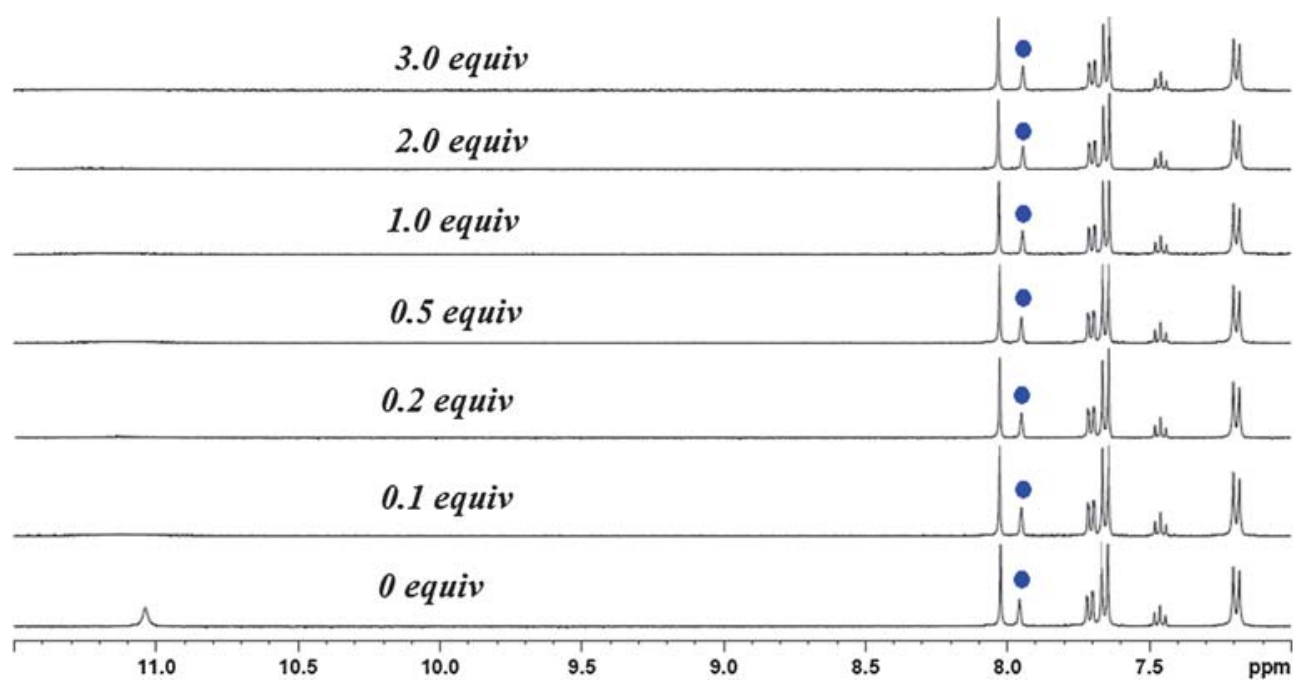

Figure 5. ${ }^{1} \mathrm{H}-\mathrm{NMR}$ titration of NBCBIH $\left(1 \times 10^{-3} \mathrm{M}\right)$ in DMSO- $\mathrm{d}_{6}$ with a standard solution of TBAF $\left(10^{-2} \mathrm{M}\right)$. The blue dot symbol in the figure shows the shift in ${ }^{1} \mathrm{H}$ NMR peak positions after gradual addition of $\mathrm{F}^{-}$. 


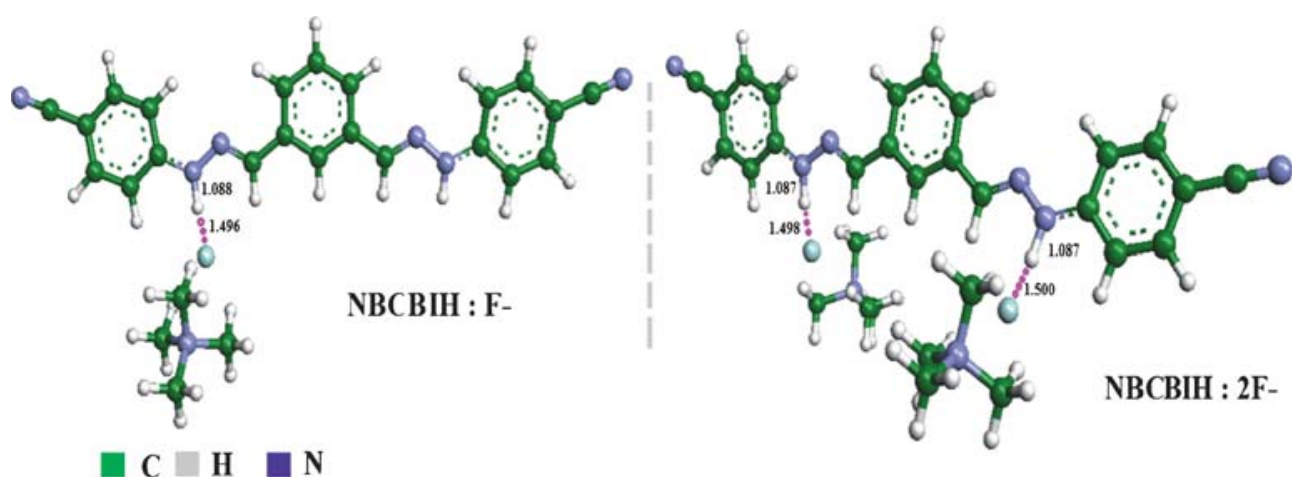

Figure 7. The geometry optimized structures of NBCBIH..F ${ }^{-}$complexes $(1: 1$ and 1:2) at BP86(D3BJ)/def2-SVP level.

protons and the aromatic protons (7.8-7.3) ppm, after interaction with incoming anion fluoride, remain unaltered suggesting that the electron density on phenyl ring is mostly unaltered; concomitantly, it strongly supports $\mathrm{H}$-bonded weak interaction between NBCBIH and $\mathrm{F}^{-}$.

\subsection{Infrared Spectroscopic analysis}

Infrared spectrum of NBCBIH can be divided into three regions 3500 to $3000 \mathrm{~cm}^{-1}, 2500$ to $2000 \mathrm{~cm}^{-1}$ and $2000 \mathrm{~cm}^{-1}$ to $500 \mathrm{~cm}^{-1}$. The FTIR spectrum of the NBCBIH.. $\mathrm{F}^{-}$complex (Figure 6) shows significant shifting of bands and intensity changes due to binding of $\mathrm{F}^{-}$. On addition of TBAF, the peak at $3263 \mathrm{~cm}^{-1}$ gets almost flattened indicating interaction of $\mathrm{F}^{-}$with the NH protons. The peak at $2210 \mathrm{~cm}^{-1}$ which is the peak for $-\mathrm{CN}$ (cyano) remains intact. The region of 2000 to $500 \mathrm{~cm}^{-1}$ shows diminished intensity and gets flattened suggesting greater electronic distribution in NBCBIH+TBAF.

\subsection{DFT-D3 Study}

In order to understand the mode of host-guest interaction, either based on abstraction of protons or H-bonding interaction, DFT-D3 calculation has been executed (Figure 7, Tables S5-S6 in SI). ${ }^{1} \mathrm{H}$ NMR study showed that during binding of NBCBIH and $\mathrm{F}^{-}$, there is no evidence towards formation of HF or $\mathrm{HF}_{2}^{-}$. In general, it is found that presence of acidic hydrogen connected to the hetero atom like $\mathrm{N}$ is responsible as $\mathrm{F}^{-}$scavenger or can build up a strong anion- $\pi$ interaction. However, in the present scenario, the formation of supramolecular $\mathrm{H}$-bonding interaction between NBCBIH and $\mathrm{F}^{-}$depicts less acidic nature of NBCBIH. For a better understanding, a detailed computational calculation was performed to evaluate the sensing nature of NBCBIH towards $\mathrm{F}^{-}$.

The $\mathrm{NH}$ distance in the crystal structure is found to be $0.86 \AA$. Interestingly, on interaction with $\mathrm{F}^{-}$in $1: 1$ host-guest interaction the $\mathrm{NH}$ distance elongates to $1.088 \AA$. The interaction distance between the hydrogen and fluoride is found to be $1.496 \AA$. Typical Hbond distances are found to be $2-3 \AA$. So the distance between $\mathrm{H}$ and $\mathrm{F}^{-}$suggests strong interaction. The final single point energy is found to be $-1489.57 \mathrm{eV}$. For 1:2 interaction, $\mathrm{F}^{-}$interacts with the other $\mathrm{NH}$ hydrogen and similarly the $\mathrm{NH}$ distance of the other arm elongates to $1.087 \AA$ with the H-bonding distance to be $1.50 \AA$. The final single point energy is found to be $-1803.54 \mathrm{eV}$. The energy difference between the $1: 1$ and 1:2 complexes is found to be $313.97 \mathrm{eV}$.

\section{Conclusions}

In summary, a hydrazine based new NBCBIH chemosensor has been synthesized which is selective for $\mathrm{F}^{-}$ over other anions like $\mathrm{Cl}^{-}, \mathrm{Br}^{-}, \mathrm{I}^{-}, \mathrm{NO}_{3}^{-}, \mathrm{HSO}_{4}^{-}$and $\mathrm{CN}^{-}$with appreciable binding constant. The color of NBCBIH turns from colorless to yellow in presence of $\mathrm{F}^{-}$. The quenching of fluorescence indicates Photoinduced electron transfer (PET) as $\mathrm{F}^{-}$gradually comes close to $\mathrm{NH}$ and $\mathrm{CH}$ sites along the side arms of NBCBIH. The DFT calculations were done on the interaction of $\mathbf{N B C B I H . . . \mathbf { F } ^ { - }}$ to validate the mechanism of PET operating in the system, where it is clear that strong $\mathrm{H}$-bonding exists between the host and the guest which is responsible for reduction in oxidation potential of the hydrazine linker in turn which triggers PET from hydrazine linkage to the phenyl subunit (vide section 3.5). Our success in developing this kind of hydrazine based chemosensor for selective detection of $\mathrm{F}^{-}$with dangling side arms is not only synthetically facile but also has enormous potential for practical purposes.

\section{Supplementary Information (SI)}

Additional information on characterization of NBCBIH using IR spectrum (Figure S1), ESI-MS spectra (Figures S2, S5), 
${ }^{1} \mathrm{H}-\mathrm{NMR}$ spectrum (Figure S3), colorimetric detection (Figure S4, S7), plot of emission intensity $v s$ concentration of $\mathrm{F}^{-}$(Figure S8), B-H plot of NBCBIH with $\mathrm{F}^{-}$(Figure S9), Jobs plot of NBCBIH with $\mathrm{F}^{-}$(Figure S10), cyclic voltammetry (Figure S11), crystallographic data (Tables S1-S4) and atomic coordinates for the energy minimized structures (Tables S5, S6) and CCDC 1498133 containing the crystallographic data for NBCBIH are given in the supplementary information, available at www.ias.ac.in/chemsci.

\section{Acknowledgements}

PB is thankful to Director, CSIR-CMERI for his support of this work. Financial support received from DST funded project (GAP 214312) under WTI vide DST/TM/WTI/2k16/277 is gratefully acknowledged. ARC is also thankful to Supra institutional research grant for her project senior research fellowship.

\section{References}

1. (a) Bose P, Dutta R, Ravikumar I and Ghosh P 2011 Optical detection of sodium salts of fluoride, acetate and phosphate by a diacylhydrazine ligand by the formation of a colour alkali metal complex J. Chem. Sci. 123 869; (b) Datta B K, Kar C and Das G 2015 Fluorescent naphthalene-based benzene tripod for selective recognition of fluoride in physiological condition J. Chem. Sci. 127 337; (c) Peng X, Wu Y, Fan J, Tian M and Han K 2005 Colorimetric and ratiometric fluorescence sensing of fluoride: tuning selectivity in proton transfer J. Org. Chem. 7010524

2. Batista R M F, Oliveira E, Costa S P G, Lodeiro C, Manuela M and Raposo M 2007 Synthesis and ion sensing properties of new colorimetric and fluorimetric chemosensors based on bithienyl-imidazoanthraquinone chromophores Org. Lett. 93201

3. Kleerekoper M 1998 The role of fluoride in the prevention of osteoporosis Endocrinol. Metab. Clin. North Am. 27441

4. (a) Roy Chowdhury A, Ghosh P, Saha S K, Mitra P and Banerjee P 2014 Exploratory studies towards various anion recognition chemistry by two different sized cleft shaped organic ligands Spectrochim. Acta Part A $\mathbf{1 2 4}$ 492; (b) Ghosh P, Kumar N, Mukhopadhyay S K and Banerjee P 2016 Sensitive and fluorescent Schiff base chemosensor for pico molar level fluoride detection: In vitro study and mimic of logic gate function Sens. Actuators, B 224 899; (c) Ghosh P, Roy B G, Mukhopadhyay S K and Banerjee P 2015 RSC Adv. 5 27387; (d) Ghosh P, Roy B G, Jana S, Mukhopadhyay S K and Banerjee P 2015 Phys. Chem. Chem. Phys. 17 20288; (e) Roy Chowdhury A, Ghosh P, Roy B G, Mukhopadhyay S K, Mitra P and Banerjee P 2015 A simple and dual responsive efficient new Schiff base chemoreceptor for selective sensing of $\mathrm{F}^{-}$and $\mathrm{Hg}^{2+}$ : Application to bioimaging in living cells and mimicking of molecular logic gates $R S C A d v .5$ 62017; (f) Roy Chowdhury A, Ghosh P, Roy B G, Mukhopadhyay
S K, Murmu N C and Banerjee P 2015 Cell permeable fluorescent colorimetric Schiff base chemoreceptor for detecting $\mathrm{F}^{-}$in aqueous solvent Sens. Actuators, $B 220$ 347; (g) Roy Chowdhury A, Ghosh P, Paul $\mathrm{S}$, Bhuyan S, Bose K J C, Mukhopadhyay S and Banerjee P 2017 A novel ditopic chemosensor for cadmium and fluoride and its possible application as a $\mathrm{pH}$ sensor Anal. Methods 9 124; (h) Roy Chowdhury A, Roy B G, Saibal J, Weyhermuller T and Banerjee P 2017 A simple cleft shaped hydrazine-functionalized colorimetric new Schiff base chemoreceptor for selective detection of $\mathrm{F}^{-}$in organic solvent through PET signaling: Development of a chemoreceptor based sensor kit for detection of fluoride Sens. Actuators, B 241706

5. (a) Saravanakumar D, Devaraj S, Iyyampillai $S$, Mohandoss K and Kandaswamy M 2008 Schiff's base phenol-hydrazone derivatives as colorimetric chemosensors for fluoride ions Tetrahedron Lett. 49 127; (b) Zhao Y-G, Zhang B-G, Duan C-Y, Lin Z-H and Meng Q-J 2006 A highly selective fluorescent sensor for fluoride through ESPT signaling transduction New. J. Chem. 30 1207; (c) Sharma D, Sahoo S K, Chaudhary S, Bera R K and Callan J F 2013 Fluorescence 'turn-on' sensor for $\mathrm{F}^{-}$derived from vitamin $\mathrm{B}_{6}$ cofactor Analyst 138 3646; (d) Mahapatra A K, Manna S K and Sahoo P 2011 Color response of tri-armed azo host colorimetric sensors and test kit for fluoride Talanta $\mathbf{8 5} 2673$

6. (a) Li Y, Lin H, Cai Z and Lin H 2011 Colorimetric Sensing of Biologically Important Acetate Ion Based on Indole Derivation Mini Rev. Org. Chem. 8 25; (b) Y-G Zhao, B-G Zhang, C-Y Duan, Z-H Lin and Q-J Meng 2006 A highly selective fluorescent sensor for fluoride through ESPT signaling transduction New J. Chem. 30 1207

7. (a) Hauser C M S, Mereiter K, Schmid R and Kirchner K 2003 Formation of ruthenium-aminocarbene complexes from aldimines and aminals Eur. J. Inorg. Chem. 1883; (b) Hauser C M S, Mereiter K, Schmidb R and Kirchner K 2002 Novel ruthenium-mediated conversion of aldimines and aminals to aminocarbene complexes Organometallics 214891

8. (a) Adams H, Bailey N A, Rodriguez de Barbarin C O, Fenton D E and He Q Y 1995 Heteroleptic tripodal complexes of copper(II): towards a synthetic model for the active site in galactose oxidase J. Chem. Soc. Dalton Trans. 2323; (b) Kang S G, Kimand S J and Jeong J H 1998 Synthesis and properties of a tetraaza macrocyclic ligand containing 2-pyridylmethyl pendant arms and its copper(II) and nickel(II) complexes: Crystal structure of the copper(II) complex Polyhedron 17 3227

9. (a) TURBOMOLE: Program Package for ab initio Electronic Structure Calculations. www.turbomole.com. (accessed on 15 March 2017); (b) Ahlrichs R, Bar M, Haser M, Horn H and Kolmel C 1989 Synthesis and properties of a tetraaza macrocyclic ligand containing 2-pyridylmethyl pendant arms and its copper(II) and nickel(II) complexes: Crystal structure of the copper(II) complex Chem. Phys. Lett. 162 165; (c) Schafer A, Horn H and Ahlrichs R 1992 Fully optimized contracted Gaussian basis sets for atoms $\mathrm{Li}$ to $\mathrm{Kr}$ J. Chem. Phys. 972571 
10. Gogoi A, Samanta S and Das G 2014 A benzothiazole containing $\mathrm{CHEF}$ based fluorescence turn-ON sensor for $\mathrm{Zn}^{2+}$ and $\mathrm{Cd}^{2+}$ and subsequent sensing of $\mathrm{H}_{2} \mathrm{PO}_{4}^{-}$ and $\mathrm{P}_{4} \mathrm{O}_{7}^{4-}$ in physiological pH Sens. Actuators, B 202 788

11. Ghosh P, Roy Chowdhury A, Saha S K, Ghosh M, Pal M, Murmu N C and Banerjee P 2015 Synthesis and characterization of redox non-innocent cobalt(III) complexes of a O,N,O donor ligand: Radical generation, semi-conductivity, antibacterial and anticancer activities Inorg. Chim. Acta 42999

12. Ghosh P, Roy Chowdhury A, Corbella M, Bhaumik A, Mitra P, Mobin S M, Mukherjee A, Basu S and Banerjee, P 2014 Designed synthesis of $\mathrm{CO}_{2}$-promoted copper(II) coordination polymers: Synthesis, structural and spectroscopic characterization, and studies of versatile functional properties Dalton Trans. 43 13500

13. Presow S R, Ghosh M, Bill E, Weyhermüller T and Wieghardt K 2011 Molecular and electronic structures of new iron complexes containing N,S-coordinated o-iminothionebenzosemiquinonate(1-) $\pi$ radical ligands: an experimental and density functional theoretical study Inorg. Chim. Acta $\mathbf{3 7 4} 226$

14. Sivakumar R, Reena V, Ananthi N, Babu M, Anandan S and Velmathi S 2010 Colorimetric and fluorescence sensing of fluoride anions with potential salicylaldimine based schiff base receptors Spectrochim. Acta Part A 75 1146

15. Saravanakumar D, Devaraj S, Iyyampillai S, Mohandoss, K and Kandaswamy M 2008 Schiff's base phenol-hydrazone derivatives as colorimetric chemosensors for fluoride ions Tetrahedron Lett. 49127

16. Hammud H H, Ghannoum A and Masoud M S 2006 Spectral regression and correlation coefficients of some benzaldimines and salicylaldimines in different solvents Spectrochim. Acta Part A 63255

17. Ghatak S K, Dey D, Sen S and Sen K 2013 Aromatic amino acids in high selectivity bismuth(III) recognition Analyst 1382308
18. de Silva A P, Moody T S and Wright G D 2009 Fluorescent PET (Photoinduced Electron Transfer) sensors as potent analytical tools Analyst 1342385

19. (a) Pan Z-H, Luo G-G, Zhou J-W, Xia J-X, Fang K and Wu R-B 2014 A simple BODIPY-aniline-based fluorescent chemosensor as multiple logic operations for the detection of $\mathrm{pH}$ and $\mathrm{CO}_{2}$ gas Dalton Trans. 43 8499; (b) Kavarnos G J and Turro N J 1986 Photosensitization by reversible electron transfer: Theories, experimental evidence, and examples Chem. Rev. 86 401; (c) Verma P, Sawanta R M and Pal H 2015 Intriguing multichannel photoinduced electron transfer in lanthanide(III)diphenylamine systems Phys. Chem. Chem. Phys. 17 23214

20. (a) Mashraqui S H, Ghorpade S S, Tripathi S and Britto S 2012 A new indole incorporated chemosensor exhibiting selective colorimetric and fluorescence ratiometric signaling of fluoride Tetrahedron Lett. 53 765; (b) Mahapatra A K, Manna S K and Sahoo P 2011 Color response of tri-armed azo host colorimetric sensors and test kit for fluoride Talanta 85 2673; (c) Mukherjee S, Paul A K and Stoeckli-Evans H 2014 Color response of tri-armed azo host colorimetric sensors and test kit for fluoride Sens. Actuators, B 202 1190; (d) Schramm A D S, Nicoleti C R, Stock R I, Heying $R$ S, Bortoluzzi A J and Machado V G 2017 Anionic optical devices based on 4-(nitrostyryl)phenols for the selective detection of fluoride in acetonitrile and cyanide in water Sens. Actuators, B 240 1036; (e) Wu Y-C, Huo J-P, Cao L, Ding S, Wang L-Y, Cao D and Wang Z-Y 2016 Design and application of tri-benzimidazolyl starshape molecules as fluorescent chemosensors for the fast-response detection of fluoride ion Sens. Actuators, B 237865

21. (a) Gomez D E, Fabbrizzi L, Licchelli $M$ and Monzani E 2005 Urea vs. thiourea in anion recognition Org. Biomol. Chem. 3 1495; (b) Boiocchi M, Boca L D, Gomez D E, Fabbrizzi L, Licchelli M and Monzani E 2005 Anion-induced urea deprotonation Chem. Eur. J. 113097 